\title{
Study the Corrosion Inhibition of Carbon Steel in 1 M HCl Using Extracts of Date Palm Waste
}

\author{
Ghadah M. Al-Senani and Mashael Alshabanat
}

Department of Chemistry, College of Science, Princess Nourah bint Abdulrahman University, Riyadh, Saudi Arabia

E-mail: gmalsnany@pnu.edu.sa,ghada-moh@hotmail.com

doi: $10.20964 / 2018.04 .03$

Received: 25 November 2017 / Accepted: 17 January 2018 / Published: 6 March 2018

In this study, extracts of both treated and untreated date palm tree waste were used as inhibitors of carbon steel corrosion in $1 \mathrm{M} \mathrm{HCl}$. The date palm wastes used were the fiber and leaflets of the plant, and the treatment process involved gum arabic solution. The electrochemical measurements showed that the extracts were efficient inhibitors. The treated wastes were more efficient inhibitors than untreated waste, and the leaflets were better inhibitors than the fibers. The effect of temperature on inhibition efficiency, thermodynamic parameters, and adsorption isotherms for the treated inhibitors were studied. It was found that the adsorption was endothermic, occurred spontaneously, and that the adsorption data fit Langmuir isotherm model.

Keywords: Carbon steel, Hydrochloric acid, Corrosion inhibition, Date palm, Adsorption

\section{FULL TEXT}

(C) 2018 The Authors. Published by ESG (www.electrochemsci.org). This article is an open access article distributed under the terms and conditions of the Creative Commons Attribution license (http://creativecommons.org/licenses/by/4.0/). 